\title{
Acquisition of English Tough Construction by Chinese Learners of English as Second Language
}

\author{
Yafeng Zhang \\ School of Applied Techniques \\ Huanghe Science and Technology University (HHSTU) \\ Jiyuan, China
}

\begin{abstract}
English Tough Construction is one of the most difficult and delayed sentence structures in English in both first language acquisition and second language acquisition.It is reported that even advanced learners did not reach the ultimate attainment, while in Chinese a similar structure also can be found, which might well be a facilitator or impeller in second language acquisition. The present study investigates how Chinese learners of English acquire English Tough Construction.After viewing the literature of English Tough Construction and its acquisition, including Chomsky's Whmovement theory, Reider's NP-movement account of English TC and Huang Churen's theory on lexical nature of Chinese Tough Construction, An operational definition was put forward of Chinese $\mathrm{Nan} / \mathrm{Yi}$ Construction and thought that Chinese similar structure involves a syntactic as well as a lexical reading, in light of which, the research questions to be addressed in this study are: (1) Can the $L 2$ acquisition of English TC by Chinese speakers be accounted for by semantic transparency outlined by Yamaoka? (2) What role does L1 transfer play in the acquisition? (3) What role does proficiency play in the acquisition? To answer the three research questions, two possible factors are identified: animacy and L1 transfer which can be manifested by the semantic role hierarchy and role of proficiency. Inspired by Schwartz\&Sprouse's Full Transfer/Full Access theory, the first hypothesis and its empirical manifestation was put forward: the interlanguage of beginner level Chinese learners of English will show a semantic role hierarchy which is more similar to that of their mother tongue Chinese; the interlanguage representation of ETC will show a more target-like semantic role hierarchy in keeping up with proficiency. Chinese speakers will represent lexicalized ETC as derivational adjectives rather than ETC in interlanguage. Modelled on Yamaoka's semantic transparency of ETC and Zhang's Semantic Salience Hierarchy Model with animacy, we propose the second hypothesis: the learner will perform better with inanimate nouns as subject than animate nouns in the acquisition.To testify the hypotheses mentioned above, a research experiment was designed to collect information on the $L 2$ acquisition of English TC.The result shows that the advanced learners do not reach the ultimate attainment yet. The semantic role hierarchy of beginner level is similar to that of their native language. Most of learners prefer to represent the lexicalized TC as adjectives. Animacy plays a significant role in the process of acquisition of TC. A natural order of semantic role is found: nanimate patient>inanimate locative>inanimate instrument>inanimate manner. It is also found that a U-shaped behavior is manifested concerning the role of proficiency.
\end{abstract}

Keywords-Tough Construction; Chinese Nark Construction; English Proficiency Level; Animacy; Semantic Role; Crosslinguistic Influence

\section{INTRODUCTION}

Since the 1970s, there has been a proliferation of researches examining second language acquisition (SLA) in general and of grammar in particular. Not only is the amount of research impressive, but the broad range of approaches taken and the number of structures examined add to the diverse nature of this area of research [1]. If we consider SLA research as a large, unfinished puzzle [2], research pertaining to second language (L2) grammatical development constitutes one section of that puzzle. The issue touched on in this paper is "what does the first language (L1) knowledge contribute to the acquisition of tough construction (TC) which is syntactically complex." First of all, some basic theories have to be made explicit surrounding the TC, so that you can have basic background information about research issue.

\section{LITERATURE REVIEW}

\section{A. Tough Construction and Its Acquisition}

TC, also commonly described as "easy-to-please" construction, derived its name from the so-called Tough predicate. This class includes at least six adjectives: easy, hard, difficult, simple, tough, and impossible. Postal [3] proposed that TC itself was derived from the transformational rule of tough movement (TM). This rule took a sentence such as (la) as input and returned a sentence such as (1b) as its output:

- $\quad$ It is easy to please John.[1a]

- John is easy to please.[1b]

In order to account for the grammaticality of sentence like (1), N. Chomsky [4] proposed an analysis in which the deep structure (D-structure) underlying (1) contains an embedded complement clause, The matrix subject position in (1b) is non- $\theta$-position and is therefore left empty at Dstructure in accordance with the $\theta$-criterion. The subject of 'to please' is in a position, to which a $\theta$-role is assigned and assumed to be the null element PRO. Moreover, the verb 'please' also has an object $\theta$-role to assign. Chomsky 
maintains his earlier position that Wh-movement is involved in the derivation of these constructions. In this analysis PRO is inserted in the embedded object position at D-structure and subsequently moves to complement leaving a co-indexed trace in its origin position.M.Reider [5] proposed the noun phrase movement (NP-movement) account for the TC to overcome shortcomings to Chomskian analysis, while Mandarin Chinese, with configurationally defined grammatical functions and case marking, is typologically different from Japanese, Korea, or English. Huang [6] shown that tough construction in Mandarin Chinese involves both morpho-lexical process and syntactic operation. The lexical nature of Mandarin TC is established with several tests.

Chinese learners of English often seem to make more mistakes pertaining to the acceptability of TC, either as a result of L1 influence, overgeneralization, subject raising or other unknown reasons. Yip [7], in her study of investigating the acquisition of TC by Hong-Kong learners of English, pointed out that some structures similar to $\mathrm{TC}$ will be produced, including pseudo-TC and passivized TC(PTC). The examples will be given as follows, (where prefix* means ungrammatical sentence):

- $\quad *$ I am difficult to learn English.

- $\quad *$ They are not easy to be come mangers.

- $\quad *$ Foreigners are easy to be misunderstood.

The observation and pilot study among the students from mainland also witnessed the recurrence of the same phenomena. Even in child's first language acquisition, TC is also cumbersome [8].

The first and most widely recognized experimental study of the acquisition of TC was once conducted by C. Chomsky [9], as part of her wider study of the acquisition of complex syntactic structures in English by children over the age of five. C. Chomsky [9] identified the knowledge of four structures as "syntactically complex" and concluded that "since the children had not yet acquired adult-like ability to interpret the TC by the relatively advanced age of eight, it is apparent that fairly basic syntactic learning continues well into the school years." The children are relatively delayed in their acquisition of the TC.

Chen Jidong [10] conducted an experiment involving 87 Chinese students from different proficiency levels and 11 native speakers. She concluded that the students got better on the subject-agent relationship in subject raising structures than the subject-patient relationship in TC. Proficiency did not produce positive effect on the acquisition of TC. Dai Xiaochun [11] [12], assuming that the Chinese similar structure held the same parameter-setting, equally carried out a study to examine the L1 Influence.
B. Variables in the Acquisition of English TC

\begin{tabular}{|c|c|c|}
\hline Subject Animacy & Transitivity Type & \multicolumn{1}{|c|}{ Difficulty } \\
\hline Inanimate & verb & \\
\hline Animate & verb +pp & \\
\hline Animate & verb (less confusing) & \\
\hline Animate & verb (confusing) & most \\
\hline
\end{tabular}

Fig. 1. Scale of difficulty for learners of the English TC

Animacy, as an important semantic feature, plays a crucial role in subject assignment. Croft [13] claims that the animacy of argument role is one of the most important factors in establishing predicate-object relationship. $\mathrm{He}$ proposed an animacy hierarchy as: human>animate>inanimate. Summarizing the findings in the previous studies, it is not difficult to assume that animacy may come into play in the SLA of TC. Yamaoka [14] also proposed a semantic transparency hierarchy concerning the role of animacy. The semantic transparency hierarchy of TC can be outlined schematically as inFig.1, in which the subject animacy and transitivity type are the function of transparency of the sentence structure. In addition, Zhang Jingyu [15] also explored the role of animacy in his Semantic Salience Hierarchy Model, which can be stated as follow:

Semantic Salience Hierarchy with Animacy.

Zero CADS is more salient with inanimate Causer than with animate Causers. This is because with the former, only the stative reading is possible, while with the latter, two readings are, i.e., agentive and stative.

In terms of the Case grammar introduced by Fillmore, the most important cases in the model are the following [16]: (1) instrumental, the relationship of inanimate causer of an action or the object with which an action is accomplished; (2) patient, the role of the inanimate participant directly affected by an action. Givon (cited from [17]) proposed the notion of semantic role hierarchy for objecthood as follows: Location>patient $>$ instrument>experiencer>agent, whereas Zhang Yunqiu [18] proposed several semantic role hierarchies for objecthood in Mandarin Chinese as follows:

- (1) Typical object of patient>Atypical object of patient

- (2)Object of material> object of manner>object of instrument (non-kernel case)

Linguists are fascinated with differences between languages and the role of L1 influence or cross-linguistic differences have, at least since the advent of contrastive analysis, been a central issue for a long time in SLA research while cross-linguistic similarity has been in the background, with only occasional side references. Concerning the role of L1 influence, in the Full Transfer-Full Access (FT/ FA) hypothesis, Schwartz \&Sprouse[19][20]adopted the most extreme view of transfer: absolute L1 influence.According to the "full transfer" part of FT FA hypothesis, entirety of L1 grammar is the L2 initial state, i.e., all of the abstract syntactic properties of the L1 transfer. Although obviously extreme, FT/FA model has the appeal of being readily put to empirical test, as strong hypotheses do. 
1) The role of proficiency

Proficiency can be defined by Bussmann [16] as "the ability to function competently in one's native or in a second language, involving a sense for appropriate linguistic behavior in a variety of situations." The previous studies describe the proficiency into three subtypes: P-R Users, Intermediate, and Passers. Likewise, in the thesis we divide the proficiency into three levels: beginner level, intermediate level and advanced level. The research conducted by Chen Jidong [10] found no positive effect on the acquisition of TC in terms of the proficiency. In this thesis we will reassess the role of proficiency in SLA of TC and the interaction between proficiency and $\mathrm{TC}$.

\section{2) TC and related structures}

The target structure of this thesis is concerned with TC. However, Postal [3] proposed that the term TC itself is derived form the transformational rule of TM. Given that assumption, we have to refer to its expletive-headed counterpart. Previous studies have revealed that Chinese learners of English will be prone to use PTC, that is, TC featured a passivized tough infinitive. So PTC is also within the confine of our Research. To conclude, we found that though many researches have been conducted, few researches are carried out to examine the influence of the semantic role (S.R) and animacy, especially in the SLA of mandarin TC.

\section{METHODOLOGY}

\section{A. Research Questions}

As suggested in literature review, a semantic transparency scale was found from the SLA of TC by Japanese learners of English. What about the semantic transparency scale in the SLA by Chinese learners of English? On the basis of Huang Churen's [6] analysis of lexical nature of Chinese tough construction, the Chinese similar sentence structures can be falled into two subtypes: Chinese Nan/Yi Construction involving the lexicalized predicates and $\mathrm{Nan} / \mathrm{Yi}$ Construction involving tough movement. Based on the relationship between embedded verb and surface subject, we divide the Nan/Yi Construction into five subtypes: patient, instrument, manner, material and locative. However, little is known about how the new theory about ChineseNan/Yi Construction will have effect on the acquisition of TC. Is there a developmental sequence concerning the subjecthood of TC of different semantic roles? Is there any psychological reality in the representation of lexicalized predicates of $\mathrm{Nan} / \mathrm{Yi}$ construction? Animacy is an important factor in the acquisition. Whether will it yield positive effect on the acquisition of TC? What is the role of proficiency in the SLA of TC?

For this purpose, the current study is designed to investigate the following general research questions:

1) Can the L2 acquisition of English TC by Chinese speakers be accounted for by semantic transparency outlined by Yamaoka [14]?
2) What role does L1 transfer play in the acquisition?

3) What role does proficiency play in the acquisition?

\section{B. Research Hypotheses}

Based on Full Transfer/Full Access Hypothesis [19][20], to answer the research questions, we put forward the first hypothesis to testify the role of L1 influence in terms of the semantic role hierarchy and proficiency:

Hypothesis $1\left(\mathrm{H}_{1}\right)$ :

Regarding L1 transfer and proficiency, the interlanguage of beginner level Chinese learners of English will show a semantic role hierarchy which is more similar to that of their mother tongue Chinese; the IL representation of TC will show a more target-like semantic role hierarchy in keeping up with proficiency.

Based on Yamaoka [14] semantic transparency of TC and Zhang' Semantic Salience Hierarchy with Animacy [15], the second hypothesis can be formulated:

Hypothesis $2\left(\mathrm{H}_{2}\right)$ :

Since sentences with inanimate subjects are semantically more transparent than those with animate ones in $\mathrm{TC}$, the learner will perform better with inanimate nouns than animate nouns in the acquisition.

\section{Participants}

Participants in the study are Chinese students selected from the city of Xi'an, Shaanxi province and Ji Yuan, Henan province. There are three experimental groups and a control group:

- Groups 1: High school students. Participants are selected from the students of the grade 3 in Jiyuan high school, ranging from 16 to 19 by age. They have learned English for a minimum of six years. The number of the students is 28,6 of which are male and 22 of which are female. Most students participated the Language Proficiency Test and all scored between 60 and 80 points.

- Group 2: Sophomores major in English from Shaanxi Normal University. The participants are from different regions of China. Most of them have learned English for at least 11 years. The number of the students is 26,8 of which are male and 18 of which are female. All members of the group participated the Language Proficiency Test and scored more than 80 points.

- Group 3: Graduate candidates in grade one from Shaanxi Normal University. These participants have at least ten years experience in learning English, ranging from 21 years old to 28 years old in age. There are altogether 48 students, in which 46 students are female, accounting for the larger portion of such a group, and two are male. In such a group, all are newly admitted through the entrance examination for postgraduate, and the language proficiency test is designed just for those below the 
advanced; so it is not necessary for us to administer such a test in such a group.

- Group 4: Native speakers (two from American, one from England). All the native speakers who are learning Chinese in China are from English speaking countries.

\section{Instrumentation}

The present research employs two test papers that are different in respect to their focus, motivation and structure. One test material is an English language proficiency test. Researcher uses the results of this test as an evidence of and index to the level of achievement in English for the participants. The second task is the grammaticality judgment test.The two different types of instrument are employed for the sake of the validity of the data.

\section{1) Language proficiency test(LPT)}

This test takes the form of a doze test, provided gratefully by Zhang Jingyu [15], which consists of a short essay. There are a total of 25 items in this essay each item is followed by four possible answers, among which only one is the multiple choice and the other three are all distracters.

\section{2) Grammaticality judgment test (GJT)}

This test was designed to investigate the participant's internal representation of the target construction: TC, with the additional concern with the related structure: exposedheaded construction (EHC) and PTC. It consists of 81 sentences which can be divided into six subtypes on two different dimensions, namely, animacy, which can subdivided into animate $(+\mathrm{A})$ and inanimate $(-\mathrm{A})$ and thematic relationship between the embedded verb and the subject, which can fall into five categories, that is patient, material, manner, instrument and locative[18][21]. Each subtype includes three sentences: TC, EHC and PTC, of which the EHC and PTC are regarded as distracter and filler, respectively. Each sentence is followed by a 5-Likert scale with the number-2(100\% unacceptable) through $0(50 \%$ acceptable, $50 \%$ unacceptable) to 2 (100\% acceptable). The participants are asked to rate the sentences from intuition, rather than conscious knowledge. The reliability analysis has shown that the Cronbach a coefficient amounts to 0.7775 , suggesting the higher reliability of the test paper.

All the participants will participate in the test of GJT. So we will administer the test with the interval of a minimum of one week between the first test and second one. In order to eschew the influence of the random factors, all the new words we imagine to be for the participants have been given their Chinese renderings in GJT. The LPT, is firstly administered to avoid the possible influence from the GJT. We will give the score of the LPT and consider the students whose scores are ranging from 60 to 80 as valid participants of the beginner level and those whose scores are more than 80 as the valid participants of intermediate level.

The two tests were administrated at the middle of the second semester of 2015-2016 academic years. The GJT were at the interval of one week to avoid the interference of the GJT. The score of test sentences which can be subsumed under the same sub-type will be integrated and computed for the mean score in advance.

\section{E. Data Analysis}

In this section, we will introduce the coding and scoring system used in our analysis of the GJT. Scoring of GJT data: Recall that seven sentence structures are designed on the basis of previous studies of ETC and our analysis of the Chinese Nan/yi Construction.Judgment are made on a 5point Likert scale from $-2(100 \%$ unacceptable) to $+2(100 \%$ acceptable). Hence a minus score represent a rejection, a positive score an acceptance [15].

A Univariate analysis using a generalized linear model is performed to evaluate the effects of semantic roles and proficiencies in terms of different types of sentence constructions by means of the students' grammaticality judgment responses, with the Post Hoc result. A two-way ANOVA is run to examine the role of proficiency in different semantic roles. The three independent variables are Animacy (土 A) which includes two levels: Animate (+A) and Inanimate (-A), semantic role (S.R) (6 treatments) which embraces six different semantic roles based on the Ren[21] and Zhang's classification of object in Mandarin Chinese[18] and proficiency which is the between-group variable includes three levels: beginner level, intermediate level and advanced level. Thus a $3 * 5 * 2$ factorial design is conducted.

\section{RESULTS REPORTING}

\section{A. Result of GJT Data}

Recall that H1 states that the interlanguage (IL) of beginner level Chinese learners of English will show a semantic role hierarchy which is more similar to that of their mother tongue Chinese; the IL representation of TC will show a more target-like semantic role hierarchy in keeping up with proficiency.

The descriptive statistics of GJT has shown that, as far as ETC and related structures are concerned, the learners' responses of test sentences of ETC in terms of different combinations of animacy and semantic role can be listed, based on the value of mean score, in a descending order as follows:-A patient $>-A$ locative $>$-Amaterial $>+$ Apatient $>$ Ainstrument $>-A$ manner; the mean scores of the responses of the learners in the intermediate level of proficiency have shown that the EHC is still the most frequently and correctly employed sentence structure. As far as the TC is concerned, the mean scores of the responses in intermediate level of proficiency can be listed in a descending order as follows:Apatient $>-A$ locative $>-A$ material $>-A$ instrument/-A manner $>+A$ patient; The mean scores of the test sentences of PTC with the inanimate locative and manner subject whose number of the type is fewer than the advanced learners are below zero, suggesting that those sentences are rejected by the participants. The learners performed better in TC than the PTC in general parlance; the descriptive statistics in lower level show that among the mean scores of the GJT, EHC still occupies the highest position, followed by $\mathrm{TC}$, the mean 
scores of which can be listed in a descending order as follows:-A material>-A patient>-A locative/-Ainstrument/-A manner>-A patient. As for the PTC, most participants regarded the sentences with inanimate patient subject, locative subject and manner subject ungrammatical. In the same vein, the mean score of TC outnumber that of PTC.

The mean scores of the participants in three different levels of proficiency and those of native speakers in terms of the different combinations of the semantic role and animacy have revealed that the native speakers are prone to reject the TC with inanimate manner and inanimate material in that such two subtypes in English have not been referred to by Quirk [22]. However, the acceptance by Chinese learners and the very grammaticality in Mandarin Chinese suggests the existence of negative transfer in the acquisition of TC. For the other four subtypes, the mean and standard deviation for the GJT in terms of variety of proficiencies are shown in the table. The mean scores have indicated that native speaker outperformed the second language learner, regardless of subtypes of the sentences, except for the -A locative, in which intermediate proficiency learner has the highest acceptability of the grammaticality of the test sentences. Great gaps between the learners in higher proficiency and native speaker suggest that even the learners in higher level did not master the TC in its full version.

Summarizing the result mentioned above, the developmental sequences of TC produced by GJT can be list as follows:

- $\quad$-Apatient $>-A$ locative $>-A$ material $>+A$ patient $>-A$ instrument>-A manner (High)

- $\quad$-Apatient $>-A$ locative-A material $>-A$ instruments $>-$ $A$ manner $>+A$ patient (Intermediate)

- $\quad$-Amaterial $>-A$ patient $>-A$ locative $>-A$ instrument $>-$ A manner $>+A$ patient(Low)

Compared with the semantic role hierarchy in English and Chinese stated above, we find that the Chinese learners of English in higher proficiency demonstrated a hierarchy rather close to that of English; while the hierarchy demonstrated by the L2 learners of English in lower proficiency is rather similar to that of Chinese with a little modification. Such a result seems to validate the first part of H1. A vestige of development can be noted from the phenomenon that both the second parts of sequences of the intermediate and lower level and the first parts of sequences of the higher level and intermediate overlap each other. Meanwhile, it is not difficult to find a so-called natural order: inanimate patient>inanimate locative>inanimate instrument>inanimate manner underlying the sequences of three different levels of proficiency.

\section{1) Post hoc Results of GJT Data.}

Recall that $\mathrm{H}_{2}$ claims that since sentences with inanimate subjects are more transparent semantically than animate ones in TC, the learners will perform better with inanimate subjects than animate ones in the acquisition.
TABLE I. PAIRWISE COMPARISONS RESULTS OF + A PATIENT TYPE IN ADVANCED LEVEL

\begin{tabular}{|c|c|c|c|}
\hline Type (I) & Types (J) & $\begin{array}{c}\text { Mean } \\
\text { Deviation }\end{array}$ & $\begin{array}{c}\text { Significant } \\
\text { level }\end{array}$ \\
\hline$+\mathrm{A}^{\mathrm{a}}$ patient & $-\mathrm{A}^{\mathrm{b}}$ patient & $-0.740(* \mathrm{c})$ & 0.000 \\
\hline & - A locative & -0.182 & 0.285 \\
\hline & - A instrument & 0.328 & 0.055 \\
\hline & -A manner & $0.375\left(*^{\mathrm{a}}\right)$ & 0.028 \\
\hline & -Amaterial & 0.163 & 0.339 \\
\hline
\end{tabular}

a. $a=$ animate; $b=$ inanimate; $c *$ The mean difference is significant at the 0.05 level(here in after)

"Table I" has shown that as far as TC is concerned, the difference between $+\mathrm{A}$ patient and $-\mathrm{A}$ patient reaches the significant level $(p<0.05)$, which has suggested that animacy has produced significant effect on the acquisition of TC and that participants are prone to accept the sentences with the inanimate patient $(M . D<0)$, when compared with $+A$ patient. So is the difference between the $+\mathrm{A}$ patient and $-\mathrm{A}$ manner (M.D=0.375; $\mathrm{p}=0.028$ ) except that participants tend to accept the sentences with $+\mathrm{A}$ patient subjects, when compared with those with -A manner subjects.

TABLE II. COMPARISON RESULT OF -A PATIENT TYPE IN ADVANCED LEVEL

\begin{tabular}{|c|c|c|c|}
\hline Types (I) & Types $(\mathrm{J})$ & Mean Deviation & Significant \\
\hline -A patient & +A patient & $0.740(*)$ & 0.000 \\
\hline & -A locative & $0.557(*)$ & 0.001 \\
\hline & -A instrument & $1.068(*)$ & 0.000 \\
\hline & -A manner & $1.115(*)$ & 0.000 \\
\hline & -A material & $0.576(*)$ & 0.001 \\
\hline
\end{tabular}

According to "Table II", there is a significant difference between the $+A$ patient and-A patient $(p<.05)$, suggesting that the animacy is playing a crucial role in the acquisition of TC and confirming the Hypothesis 2. Meanwhile, patient is equally significantly different from the so-called non-kernel cases or the marked case (Yuan Yulin, 1998) and outnumbers them: locative (M.D $>0, p=0.001$ ), instrument (M.D>0, p=0.000), manner (M.D>0, p=0.000), material (M.D $>0, p=0.001)$. Such a result also verifies the validity of the Markedness Differential Hypothesis: unmarked forms are learned before the marked forms.

TABLE III. PAIRWISE COMPARISONS OF -A LOCATIVE TYPE IN ADVANCED LEVEL

\begin{tabular}{|c|l|l|l|}
\hline Types(I) & \multicolumn{1}{|c|}{ Type $(\mathrm{J})$} & \multicolumn{1}{c|}{ Mean deviation } & \multicolumn{1}{c|}{ Significant level } \\
\hline -A locative & +A Patient & 0.182 & 0.285 \\
\hline & -A Patient & $-0.557(*)$ & 0.001 \\
\hline & -A Instrument & $0.510(*)$ & 0.003 \\
\hline & -A Manner & $0.557(*)$ & 0.001 \\
\hline & -A Material & 0.019 & 0.911 \\
\hline
\end{tabular}

As shown in "Table III", the result of Pairwise comparison of -A locative type in advanced level indicates that significant differences can be found between the locative and patient $(\mathrm{p}=0.001)$, instrument $(\mathrm{p}=0.003)$ and manner $(\mathrm{p}=0.001)$, respectively, on the same dimension of animacy. It can be inferred from the fact that locative is significantly different from the patient and the difference between the -A locative and $+\mathrm{A}$ patient is not significant that animacy equally plays the crucial role in the acquisition of TC. 
TABLE IV. PAIRWISE COMPARISONS OF -A INSTRUMENT TYPE IN ADVANCED LEVEL

\begin{tabular}{|c|c|c|c|}
\hline Type $(\mathrm{I})$ & Type $(\mathrm{J})$ & Mean deviation & Significant level \\
\hline -A instrument & +A patient & -0.328 & 0.055 \\
\hline & -A patient & $-1.068\left(^{*}\right)$ & 0.000 \\
\hline & -A locative & $-0.510\left(^{*}\right)$ & 0.003 \\
\hline & -A manner & 0.047 & 0.783 \\
\hline & -A material & $-0.491\left(^{*}\right)$ & 0.004 \\
\hline
\end{tabular}

"Table IV" is the result of the Pairwise comparisons of A instrument type in the higher proficiency. It can be noted that in TC, the mean score of -A instrument type did not outnumber other subtypes with the exception of -A manner (M.D=0.047) and their differences are also statistically significant except for the $+\mathrm{A}$ patient $(\mathrm{p}=0.055)$ and $-\mathrm{A}$ manner $(p=-0.783)$. In the same vein, we can infer that animacy is playing an important role in the acquisition though the difference between-Ainstrument and $+\mathrm{A}$ patient does not reach the significant level $(\mathrm{p}>0.05)$.

TABLE V. PAIRWISE COMPARISONS OF -A MANNER TYPE IN ADVANCED LEVEL

\begin{tabular}{|c|c|c|c|}
\hline Type $(\mathrm{I})$ & Types $(\mathrm{J})$ & Mean deviation & Significant level \\
\hline -A manner & $+\mathrm{A}^{\mathrm{b}}$ patient & $-0.375\left(^{*}\right)$ & 0.028 \\
\hline & -A patient & $-1.115\left(^{*}\right)$ & 0.000 \\
\hline & -A locative & $-0.557\left(^{*}\right)$ & 0.001 \\
\hline & -A instrument & -0.047 & 0.783 \\
\hline & -A material & $-0.538(*)$ & 0.002 \\
\hline
\end{tabular}

From the "Table V", we can see that significant difference fails to be found between-Amanner type and -A instrument type. The fact that patient is significantly different from manner $(\mathrm{p}=.000)$ and $-\mathrm{A}$ manner is different from the $+A$ patient at a significant level $(p=.028)$ remains the significant role of animacy indeterminate.

TABLE VI. PAIRWISE COMPARISONS OF -A MATERIAL TYPE IN ADVANCED LEVEL

\begin{tabular}{|c|c|c|c|}
\hline Types(I) & Types $(\mathrm{J})$ & Mean deviation & Significant level \\
\hline -Amaterial & +A patient & 0.163 & 0.339 \\
\hline & -A locative & -0.019 & 0.911 \\
\hline & -A instrument & $0.491\left(^{*}\right)$ & 0.004 \\
\hline & -A manner & $0.538\left(^{*}\right)$ & 0.002 \\
\hline & -A patient & $-0.576\left(^{*}\right)$ & 0.001 \\
\hline
\end{tabular}

As revealed in "Table VI", statistically significant differences are found between -A material type and -A patient type, -A instrument and -A manner respectively. In the same vein as suggested in table 3 and 4 , inference can be made that animacy produced positive effect on the acquisition.

TABLE VII. MULTIPLE COMPARISONS OF INTERMEDIATE LEVEL

\begin{tabular}{|c|c|c|c|}
\hline Type $(\mathrm{I})$ & Type $(\mathrm{J})$ & Mean deviation & Significant level \\
\hline +A patient & -A patient & $-1.0096\left({ }^{*}\right)$ & 0.0008 \\
\hline
\end{tabular}

As shown in "Table VII", the multi-comparison of the intermediate participants has revealed that the difference between $+\mathrm{A}$ patient and $-\mathrm{A}$ patient in English TC reaches a significant level $(p=0.008)$, suggesting that animacy has produced significant effect on the acquisition of English TC for intermediate level participants.
TABLE VIII. MULTIPLE COMPARISONS OF LOWER LEVEL

\begin{tabular}{|c|c|c|c|}
\hline Type(I) & Type $(\mathrm{J})$ & Mean Deviation & Significant. \\
\hline -A manner & -A patient & $-0.7143(*)$ & 0.046 \\
\hline & -A material & $-0.7452(*)$ & 0.032 \\
\hline
\end{tabular}

According to the result of multicomparisons of lower proficiency "Table VIII", the role of manner is statistically different from the role of patient $(\mathrm{p}=.046)$ and material $(\mathrm{p}=0.032)$ on the same dimension of animacy. However, the fact that $+\mathrm{A}$ patient is also different from $-\mathrm{A}$ manner $(\mathrm{p}<0.05)$, makes the role of animacy uncertain.

In all, the animacy is playing a crucial role in the acquisition by learners in higher proficiency and intermediate proficiency and no significant difference is found in lower proficiency. So the $\mathrm{H}_{2}$ was partially confirmed.

Recall that $\mathrm{H}_{1}$ predicts that the learners with different proficiencies will be significantly different in terms of the S.R. Thus a two-way ANOVA was conducted to examine the role of proficiency in different S.R. The result in "Table IX" has indicated that proficiency produces the significant effect on the $+\mathrm{A}$ patient and $-\mathrm{A}$ patient $\left(\mathrm{F}_{(+\mathrm{A})}=3.612, \mathrm{p}<.05\right.$; $\left.\mathrm{F}_{(-\mathrm{A})}=7.102, \mathrm{p}<.05\right)$, and there is no significant difference in other four S.Rs. So the $\mathrm{H}_{1}$ was not completely confirmed.

TABLE IX. RESUlt OF BETWEEN-GROUP OF PROFICIENCY

\begin{tabular}{|c|c|c|c|c|}
\hline Semantic role & Sum of squares & Mean & $\mathrm{F}$ & $\begin{array}{c}\text { Significant } \\
\text { level }\end{array}$ \\
\hline +A Patient & 6.029 & 3.015 & 3.612 & 0.031 \\
\hline -A Patient & 7.688 & 3.844 & 7.102 & 0.001 \\
\hline -A locative & 0.633 & 0.316 & 0.358 & 0.700 \\
\hline -A instrument & 2.572 & 1.286 & 1.614 & 0.204 \\
\hline -A manner & 2.736 & 1.368 & 2.155 & 0.121 \\
\hline -A material & 0.056 & 0.028 & 0.054 & 0.948 \\
\hline
\end{tabular}

Univariate Test "Table X" is conducted to explore the main effect of construction type (C.T), Animacy and Pro, interaction between C.T and Pro as well. The result shows significant main effect of C.T $(\mathrm{F}=13.763, \mathrm{p}<0.05)$, Pro $(\mathrm{F}=4 . \mathrm{I} 43, \mathrm{p}<0.05)$ and Animacy $(\mathrm{F}=11.466, \mathrm{p}<0.05)$; the interaction between C.T and Pro also reaches the significant level $(\mathrm{F}=1.977, \mathrm{p}<0.05)$.

In conclusion, the hypotheses were confirmed in general. Information from the notes underneath the "Table X" has indicated that the $\mathrm{R}$ Squared of variable C.T is 0.153, suggesting that C.T can account for $15.3 \%$ of variances of the TC; R Squared of variable PRO is 0.281 , revealing that Pro can account for $28.1 \%$ of variances of TC; approximately, $17.7 \%$ of variances can be account for by its interaction. The total amount of the three variables can account for $61.1 \%$ of variances of TC, implicating that some other unknown factors also may play their own roles in the acquisition of TC. 
TABLE X. MAIN EFFECTS AND INTERACTION OF TC

\begin{tabular}{|c|c|c|c|}
\hline Source & Sum of square & F. & Significant level \\
\hline C. $^{\mathrm{a}}$ & 48.354 & 13.763 & 0.000 \\
\hline PRO $^{\mathrm{b}}$ & 5.823 & 4.143 & 0.016 \\
\hline Animacy & 39.880 & 11.466 & 0.000 \\
\hline CT $^{*}$ Pro $^{\mathrm{c}}$ & 13.891 & 1.977 & 0.034 \\
\hline & b. & a. $\mathrm{R}^{2}=0.153$ (Adjusted $\mathrm{R}^{2}=0.128$ ) & b. $\mathrm{R}^{2}=0.281$ (Adjusted $\mathrm{R}^{2}=0.261$ ) \\
& \multicolumn{3}{|c}{ c. $\quad$ c. $\mathrm{R}^{2}=0.177$ (Adjusted $\mathrm{R}^{2}=0.153$ ) }
\end{tabular}

\section{DISCUSSION}

Our study has yielded such results:

- The result of chapter five has indicated that the mean score of EHC is the highest, no matter whether the learners can be subsumed under beginner level, intermediate level, advanced level, or native speaker, which confirms the findings made by Yip [7] that learners have the tendency to overrely on the EHC.

- Animacy plays a significant role in the acquisition of TC in advanced and intermediate level; whereas no significant difference can be found in the lower proficiency. So the $\mathrm{H}_{2}$ is partially confirmed.

- The so-called U-shaped behaviors are noted in the different levels of proficiency for the acquisition of TC with different combination of semantic role and animacy, which rejects the latter part of the $\mathrm{H}_{1}$.

- The interaction between CT and Pro is statistically significant.

Animacy is an important factor to influence students' judgment of the acceptability of test sentences. While what should be noted is that for learners in low proficiency, the animacy did not produce the positive effect with the possible reason that the low competence in English confines their awareness of English as typical subject-prominent language.

\section{A. Semantic Role}

As far as semantic role is concerned, developmental sequences derived from the result of GJT can be listed according to the mean scores in the descending order. They will be summarized here for clarity:

- $\quad$-A patient $>$-Alocative $>-$ Amaterial $>+A$ patient $>-A$ instrument $>$-A manner (High)

- $\quad$-Apatient $>-A$ locative $>$-Amaterial $>-A$ instrument $>$ A manner $>+A$ patient (Intermediate)

- $\quad$-A material $>-A$ patient $>-A$ locative $>-A$ instrument $>-$ A manner $>+A$ patient (Low)

The developmental sequences demonstrate a very apparent transition from the lower proficiency to higher proficiency. In the sequence of lower proficiency, -A material enjoys the highest position. It seems to convince us the pervasive influence from L1 for the fact that most native speakers reject the sentence like:

- $\quad *$ The paint is not easy to brush.
While most participants in beginner level accept it, because of the acceptability of its corresponding Chinese rendering:

- 涂料/油漆不好刷。

Paint is not easy to paint.

Meanwhile, it is not difficult to find the commonality underlying the developmental sequences; that is the order ofpatient >-A locative-A instrument>-A manner remains invariant regardless of its proficiency, suggesting some kind of so-called UG component underlying the sequence. What is different in between is the position of+Patient and -A material in different stages.

\section{B. Proficiency}

Learner's level of proficiency also seems to be a relevant factor in determining when transfer will occur. In the present study, the results of table 1 through table 10 have indicated that higher proficiency and intermediate proficiency have yielded positive effect on animacy. Nevertheless, no significant difference is found between lower proficiency and animacy as shown in Table 12. Where the semantic role is concerned, a so-called "U-shaped behavior" is noted; A "U-shaped behavior' has ever been noted by Kellerman (cited from[24]). It means that the acceptability of sentences was initially low, then rose, and finally fell again in inanimate material, inanimate locative, and inanimate instrument in the three levels of proficiency; Animate patient, conversely, was initially high, then fell, and finally rose again, giving the "U" shape to a graphic representation of the comprehension data. The acceptability of animate patient increases as the proficiency is improved. The inanimate material and inanimate manner roughly keep the constant trend throughout the graph. It can be inferred from those facts that not the proficiency alone was playing the crucial role in the acquisition of TC. The proficiency may interact with other variables.

It should be pointed out that bulk of Chinese lexicon is composed of a combination or collocation of two Chinese characters with one of which carrying the principle meaning. It is also interesting to point out that both 'walk' and 'zou'are synonymous, for example. The student could assume that if the word 'walk' means move with two feet and the character 'zou'means move with two feet; so 'walk' equals 'zou'with the same semantic and syntactic function. In fact we use 'zoulu' (walk) as stereotyped use of such a concept; however, such a corresponding literal translation is not permitted in English for the verb 'walk' to be an intransitive verb. So error of transitivity are mainly caused by the fact that certain concept is lexically represented by transitive verb in English but by intransitive verbs in Chinese, or vise versa.

What is more, we have to give a rough explanation concerning the mechanism to ensure the lexical nature of predicates. Yutata Furukawa [25] takes up the position that such different types of tough predicates involve the backgrounding of subject and foregrounding of the object. It can be diagrammed in "Fig. 2": 


\begin{tabular}{|l|l|l|}
\hline Hidden verb & $\begin{array}{l}\text { two place= } \\
(\text { agent<patient }>)\end{array}$ & $\begin{array}{l}{[\mathrm{N} \text { (agent) }} \\
\text { (patient) }]\end{array}$ \\
\hline & \multicolumn{2}{|c|}{$+\mathrm{V}+\mathrm{N}$} \\
\hline Derivational adjective & one place= (patient): & {$[\mathrm{N}$ (patient)+可 $\mathrm{V}]$} \\
\hline & & {$[\mathrm{N}$ (patient)+ V 人 $]$} \\
\hline & & {$[\mathrm{N}$ (patient)+好 $\mathrm{V}]$} \\
\hline & & {$[\mathrm{N}$ (patient)+难 $\mathrm{V}]$} \\
\hline
\end{tabular}

Fig. 2. Mechanism of variation from the verb group to derivational adjective

That is, in the operation of valence reducing, the argument which will be removed from the originally twoplace verb must be the subjective noun, and the residue has to be moved to subject position from the object position. We term it as object-subject promotion. Also we can say that it involves the fact that the objective noun was foregrounded as subjective noun was backgrounded in the interest of semantic or pragmatic concern.

Some other individuals [26][27][28]thought that it is the result of grammaticalization. Let's first of all recall the cline of grammaticality by Hopper as follows: Content item> grammatical word $>$ clitic $>$ inflectional affix (cited from[29]). The highest layer of the hierarchy was content item; then the lexical item in certain stage may become a grammatical word in the next stage, then more grammatical.

We will take the case of the character 'hao' to explain my view. Li Jinxia [26] stated the process of grammaticalization in her article: before the Han dynasty, the "hao" was employed as adjective alone. As the time elapses, Tang dynasty has witnessed the advent of 'hao'as premodifier of the verb. It was gradually becoming the favorites until Ming emperor," functioning as a prefix" [30].

\section{CONCLUSION}

The major results are summarized and discussed within the FT/FA hypothesis and semantic transparency scale. Unlike the native speakers, L2 speakers' acceptance to the English TC (including the typical and atypical types) varies in light of the semantic transparency of the structure with different semantic roles between the embedded verb and the subject, to the cognitive factor animacy and different proficiency levels. Crosslinguistic influence (CLI) was found with reference to the second language learners' acceptance to some ungrammatical English TCs in GJT whose Chinese correspondences are permitted as grammatical. L2 learners are more accurate with inanimate subject than animate subject, revealing the role of animacy and confirming the semantic transparency scale. As far as the TC and its related structure are concerned, learners' overreliance on the EHC also confirmed the role of semantic transparency in the SLA of TC for EHC to be semantically most transparent. However, it seems that advanced learners did not completely acquire the TC and the acceptance of the sentences with different S.Rs by advanced learners was in inverse proportion to the proficiency.
Also revealed is the interaction of factors involved in the IL of the development of TC. L2 representation of ETC at any stage is the result of integration of CLI, animacy, S.R, universal grammar component and proficiency level. Optionality in interlanguage grammar is the trend during the intermediate stage of interlanguage development.

\section{ACKNOWLEDGMENT}

First of all, I would like to give my sincere gratitude to Prof. Zhang Jingyu, my tutor, for his patient guidance and constructive suggestions on my paper. Second, I would like to express my heartfelt gratitude to the Professor Tian Bing, Professor He Junjie, Professor Bai jingyu and many other professors in Shaan Xi Normal University for their insightful lectures and advice, from which, I have benefited a lot and academically prepared for the paper. Special thanks also should go to my friend $\mathrm{Li}$ Zhaolong who has put considerable time and effort into data collection and to those students who have participated into the research. Last my thanks would go to my beloved family for their loving considerations and great confidence in me.

\section{REFERENCES}

[1] Braidi S. M., The Acquisition of Second Language Syntax, London: Arnold. 1954.

[2] Gass S. M., "Language universal and second language acquisition." Language Learning, vol. 39, pp. 497-534,1989.

[3] Postal,P.\&Ross, J., "Tough movement si, tough deletion no!". Linguistic Inquiry,vol.2, pp.544-546, 1971.

[4] Chomsky, N., Lectures on Government and Binding. Dordrecht, the Netherlands:Foris. 1981.

[5] Reider, M. "An NP-Movement account of tough construction." Kansas Working Papers in Linguistics, vol.21, pp.99-121, 1996.

[6] Huang Churen. "Morphological Transparency and Autonomous Morphology: A Comparative Tough Construction and Nominalization." Chinese language and Linguistics II:Morphology and Lexicon. Taipei: institute and philology,Academia Sinica.1997, pp. 369-399.

[7] Yip, V. Interlanguage and Learn Ability: from Chinese to English. Amsterdam:John Benjamins Publishing Company. 1995.

[8] Anderson, D.L. The First Language Acquisition of the Tough Construction, Ph.D. dissertation. Cambridge: University of Cambridge. 2005.

[9] Chomsky, C. The acquisition of syntax in Children from 5 to 1. MA: MIT Press.1969.

[10] Chen Jidong, "Exploration of IP in the acquisition of english tough construction", Journal of Modern Language.vol. 24, pp. 159-69, 2001.

[11] Dai Xiaochun, "Syntactic contrast between English tough construction and Nan/yi construction in Chinese", Journal of Hunan first Normal University, vol.2, pp. 62-52, 2002a.

[12] Dai Xiaochun, "First language transfer in the acquisition of English tough construction".Journal of Shaoyang College, vol. 1, pp.123-126, 2002 b.

[13] Croft, W., Typology and Universals. Cambridge: Cambridge University Press. 1995.

[14] Yamaoka, Toshihiko., "A semantic and prototype discussion of the "be easy to v"structure: a possible explanation of its acquisition process." Applied 1988. 
[15] Zhang, Jingyu., The Acquisition of Psych-predicates by Chinesespeaking Learners of English: a Semantic Salience Hierarchy Model. Ph.D.dissertation. Guangzhou: Guangdong University of Foreign Studies. 2002.

[16] Bussmann, H., Routledge Dictionary of Language and Linguistics. Beijing:Foreign Language Teaching and Research Press. 2000.

[17] Wang, Yunfeng., L2 learning of English Passive by Chinese Learners. $\mathrm{Ph} . \mathrm{D}$. dissertation. Guangzhou:Guangdong University of Foreign Studies. 2001.

[18] Zhang Yunqiu., Reseach into the Sentences with Patient-object in Mandarin Chinese.Shanghai:Xuelin Press. 2004.

[19] Schwartz, B.\&Spouse, R. "Word order and nominative case in nonnative language acquisition."In Hoekstra,T.\&Schwartz, B. (Eds.) Language Studies in Generative Grammar. Amsterdam:John Benjamins. 1994.

[20] Schwartz, B. \& Spouse, R., "L2 cognitive states and Full Transfer/Full Access model." Second Language Research, 1996, pp.40-72.

[21] Ren Ying. Research into the Sentences with No-patient Object(2nd edition). Peking:Publishing House of China's Social Sciences. 2005.

[22] Quirk, R., A Comprehensive Grammar of the English language. London:Longman Group Ltd. 1985.

[23] Yuan Yulin, Valency Grammar in Mandarin Chinese. Peking:Peking Universtiy Press. 1998

[24] Larsen-Freeman, D.\&Long, M. H. An Introduction to Second Language Acquisition Research, Beijing:Foreign Language Teaching and Research Press. 2000.

[25] Yutata Furukawa, "Midde voice in modern Chinese---the syntactic and lexical realization of voice transfer", Xing Fuyi, New development of Voice in Mandarin Chinese. Wuhan Central China Normal University Press, 2006, pp. 135-153.

[26] Li Jixia, Grammaticalization and Subjectivity of Chinese Character'hao'. Global Chinese Teaching,vol.1, pp. 44-49, 2005.

[27] Cao rui, "Lexicalization of 'rongyi(easy)'and licensed semantic interpretation". Chinese Learning,vol.1, pp. 37-40, 2007.

[28] Xiong Jinxing. "Hao+V and haohao+V". Journal of Hunan College of Science and Technology, vol.26, pp.182-183, 2006.

[29] Hopper, Paul J.\&Traugott, Elizabeth C. Grammaticalization. Beijing: Foreign Language Teaching and Research Press. 2001.

[30] Lv Shuxiang, Modern Chinese Eight Hundred Words. Peking:the Commercial Press. 1999. 